\title{
Estudos culturais
}

Renato Ortiz

A primeiravez que tomei consciência de que seriaum praticante dosEstudos C ulturais foi em B erlim, numa conferência organizada por H ermann Herlinghaus, em 1995. No ano seguinte, num seminário realizado em Stirling (Escócia), do qual Stuart H all era um dos participantes, essa sensação se reforçou, pois, ao lado de meus amigos N estor Garcia C anclini e Jesus $M$ artin Barbero, lá me encontrava como representante de algo que nunca me tinha ocorrido. 0 questionário proposto pela U niversidade de Stanford cita-me como um dos mais "sobresalientes" latino-americanistas dedicadosaosEstudosC ulturais, o que me dá grande satisfação. Entretanto, apesar dessa evidência, a imagem que tenho entre meus colegas brasileiros não se ajusta a ela. Para eles sou simplesmente sociólogo ou antropólogo, embora meus escritos, lidos e apreciados em áreas distintas, como crítica literária, arquitetura, geografia, comunicação, se encaixem mal nas fronteiras disciplinares existentes. Pessoalmente não tenho nenhuma angústia identitária, mesmo em tempos de globalização, quando muitos estão assombrados pelo afã insensato de decifrar o seu "eu" maior. Sinceramente creio que não deveríamoster nenhuma carteira de identidade, ela diz pouco sobre nossa individualidade, mas uma "carteira de diferenças", rica, complexa, indefinida, reveladora da diversidade de nossos itinerários ao longo da vida, fechando-se somente com a nossa própria morte. $M$ as, se as representações so bre meu trabalho são distintas"fora" e" dentro" do B rasil, 
é provável que os lugares nos quais elas são lapidadas digam al guma coisa sobre a atividade intelectual que desenvolvemos e pressupomos como da das, objetivamente imutáveis. Sou incapaz de responder por completo às perguntas elaboradas pela U niversidade de Stanford. M uitas das questões abordadas são para mim relativamente distantes, talvez por ser brasileiro, latino-americano, o que de certa maneira me afasta da lógica do campo universitário norte-americano. Considerarei portanto os pontos que me parecem os mais relevantes, e talvez, com o olhar um tanto estrangeiro, venha a contribuir com o debate em andamento.

O sEstudos C ulturais não existem no Brasil como área disciplinar.C laro, o interesse pelo que é produzido, seja na Inglaterra, via Escola de Birmingham, seja nos Estados U nidos, como estudos literários, pós modernidade, globalização, está presente entre nós. M as os termos da discus são são outros. $N$ ão sei se eles constituirão no futuro uma especialização acadêmica nem saberia dizer se isso seria realmente desejável. A verdade é que a institucionalização do conhecimento na effera das humanidades se encontra mais ou menos definida, constituída por disciplinas e al gumas atividades específicas, tais como comunicação e artes. M esmo nosinstitutose departamentos de Letras, as tradicionais divisões de ensino e pesquisa parecem vigorar sem maiores constrangimentos. Isso estabelece de imediato um "dentro" e um "fora", pois as perguntas sobre a possível relação entre "estudos culturais" e "estudos literários" , o destino dos "estudos culturais", sua politização ou não, nada têm de universal. Eles seguem o ritmo das mudanças ocorridas nas universidades norte-americanas, mas dificilmente exprimem a realidade brasileira e, eu acrescentaria, latino-americana. $\mathrm{N}$ a introdução de meu livro 0 próximo e o distante: Japão e modernidademundo (Brasiliense, 2000), digo que a noção de "estudos japoneses", conhecida como japonologia, somente tem sentido quando apreciada do exterior. O s japonólogos são pesquisadores, preferencialmente oriundos da Europa e dos Estados U nidos, cuja intenção é compreender a realidade desse país determinado. Passa-se o mesmo com os brasilianistas e latino-americanistas. São pessoas que se encontram "fora" do B rasil e daA mérica Latina, trabal hando geralmente em instituições norte-americanas ou européias. M as nenhum brasileiro ou latino-americano se identificaria como um brasilianista ou um latino-americanista. I sso somente ocorre quando elesmigram para uma instituição estrangeira, inserindo-se em outro mercado acadêmico. Aí, nesse momento, sua identidade profissional irá se alterar. Por isso não há japonólogos no Japão e latino-americanistas na A mé- 
rica Latina, mas sociólogos, economistas, historiadores etc. Q uando vista internamente, a realidade das áreas geográficas tem pouca consistência (inclusive teórica), vivendo mais dos influxos externos. Embora a situação não seja exatamente a mesma (os Estudos C ulturais não coincidem com uma área geográfica qualquer), algo semelhante ocorre, pois o conhecimento vem marcado pela história dos lugares nos quais os Estudos $C$ ulturais são produzidos. Teriam eles uma unidade disciplinar? C onfigurariam uma área específica do conhecimento? A resposta pode eventual mente ser positiva quando os consideramos no contexto das universidades norteamericanas, mas negativa, ou no mínimo ambígua, quando nos voltamos para a A mérica Latina. $\mathrm{N}$ o que toca ao B rasil, parece-me que a penetração dos Estudos C ulturais se faz pelas bordas, ou seja, para utilizar uma expres são de Bourdieu, na periferia do campo hierarquizado das ciências sociais, particularmente nas escolas de comunicação (o que certamente demonstra o conservantismo de disciplinas como sociologia, antropologia, literatura). Entretanto, mesmo assim, nenhuma delas se propõe a modificar o seu estatuto institucional. 0 s textos são lidos e os autores cultivados, sem que 0 conceito de "comunicação", como área específica do conhecimento ou, se quiserem, de agregação de interesses, encontre-se ameaçado.

O sEstudos C ulturais caracterizam-se por sua dimensão multidisciplinar, a quebra das fronteiras tradicionalmente estabelecidas nos departa mentose nasuniversidades. Esse é paramim um aspecto al tamente positivo no processo de renovação das ciências sociais. $N$ ão há dúvida de que 0 movimento de institucionalização do conhecimento durante o século $X X$ caminhou muitasvezespara uma espécie de fordismo intelectual, no qual as especialidades, as subdivisões disciplinares e temáticas (sociologia rural, antropologia da família, partidos políticosetc.), alimentadas sobretudo nos momentos de celebração ritual, os grandes congressos acadêmicos, implicaram a preponderância de um saber fragmentado em relação a uma visão mais "globalizadora", "totalizadora", dos fenômenos sociais (lembro que para M arcel M aussa categoria "totalidade" erafundamental na construção do objeto sociológico). N ão se pode dizer que o processo de especial ização tenha sido inteiramente negativo; de al guma maneira ele possibilitou a análise mais setal hada de certos "eventos", mas permanece a impressão de que a fragmentação existente pouco favorece 0 aprimoramento do conhecimento, vinculando-se mais aos interesses dos grupos profissionais que disputam verbas de pesquisa e posições de autoridade no campo intelectual. Entretanto, não se deve considerar a importância da multidisciplinaridade 
como algo idêntico ao "fim das fronteiras". O u cairemos na obviedade do senso comum que tem insistentemente alardeado, já no ocaso do século XX , o "fim" das ideologias, do espaço, do trabalho, da história. Seria, nesse caso, substituir uma insuficiência real por um falso problema. Asfronteiras são necessárias para a existência de um saber autônomo, independentemente das injunções externas (religião, política, provincianismo local, senso comum). A multidisciplinaridade não é pois um valor em si, mas um valor relacional (isto é, estabelece-se em relação às "verdades" disciplinares), e é preciso portanto vinculá-la a uma questão anterior: em que medida ela favorece ou não uma realização maisadequada do próprio pensamento. SeosEstudosC ulturaispropõem uma solução multidisciplinar, não émenos certo que outras alternativas podem também ser exploradas, por exemplo a transdisciplinaridade. $N$ esse caso, os horizontes disciplinares surgem não como um entrave a ser abolido, mas como ponto de partida para uma "viagem" entre saberescompartimentados.

0 tema das fronteiras pode ser ainda explorado por outro viés. A comparação com os EstadosU nidosé sugestiva. D esde a década de 1920, com a Escola de $\mathrm{C}$ hicago, a sociologia conhece nos Estados $U$ nidos um intenso movimento de institucionalização. Introduction to the science of sociology, de Park e Burguess, considerado a pequena bíblia dos sociólogos daquela cidade, foi publicado em 1921. A expansão do ensino universitário, com a criação de departamentos e institutos de pesquisa, irá multiplicar os nichos institucionais incentivando o florescimento das diferentes áreas acadêmicas. Já nos anos de 1940 diversas escolas de pensamento, como funcionalismo e culturalismo, apresentam-se como referênciasteóricasimportantes no campo intelectual norte-americano. No Brasil, para utilizar um termo caro à intelectualidade latino-americana, a institucionalização das ciências sociais é "tardia" . A "escola paulista" de sociologia, personificada na figura de Florestan Fernandes, data dos anos de 1950. N esse momento, outras disciplinas, como a antropologia, certamente existiam, mas apenas de forma incipiente, desenvolvendo-se em pontos distantes e desconectados do país e praticadas por um número bastante reduzido de pessoas (a ciência política não existia ainda como especialização). $N$ ão se pode esquecer que 0 desenvolvimento de uma rede universitária de ensino, até a reforma de 1968, era também limitado. $\mathrm{N}$ a verdade, a institucionalização das ciências sociais se consolida nos anos de 1970 e 1980 com a emergência de um sistema nacional de pós-graduação (mestrado e doutorado) apoiado pelas agências financiadoras federais (C apes, C N Pq) e estaduais (Fapesp), 
panorama que torna o Brasil hoje um país relativamente "privilegiado" comparado a seus vizinhos, pois em nenhum deles houve um desenvolvimento tão intenso das redes universitárias de pesquisa. C ontrariamente às ditaduras chilena, argentina, uruguaia, os militares brasilei ros foram " modernizadores", isto é, impulsionaram o crescimento econômico nos marcos de uma política autoritária, o que teve conseqüências importantes na reestruturação da universidade. Q uero dizer com isso que, num contexto de institucional ização restringido, as fronteiras disci plinares nunca conseguiram se impor com a mesma força e rigidez que nos Estados $U$ nidos. $\mathrm{N}$ ão houve tempo nem condições materiais para que isso acontecesse. Sem dúvida elas existem nas universidades e nos centros de pesquisa, mas são mais porosas, fluidas, permitindo uma interação maior entre os praticantes das ciências sociais. As passagens da filosofia à sociologia, da ciência política à história, da antropologia à comunicação, da sociologia à literatura, não são casos de excepcionalidade, mas constituem quase que uma regra do campo universitário. Talvez por isso o ensaio, como forma de apreensão da realidade, sobretudo na tradição latino-americana hispânica, tenha sobrevivido ao processo de formalização disciplinar. Poisé de sua natureza desres peitar a formalidade dos limites estabelecidos.

A análise da cultura constituiria um novo paradigma sistêmico? Pessoalmente não estou convencido de que as ciências sociais operem com paradigmas, no sentido que Kuhn atribui ao termo. M esmo tomando o conceito de uma maneira mais alusiva e abrangente, como sinônimo de "referência teórica", minhas dúvidas persistem. Lembro que alguns anos atrás um debate semelhante ocorreu em relação à área de comunicação. Existiria uma "teoria da informação" distinta das outras esferas de conhecimento? Seriam as escolas de comunicação o lugar privilegiado desse "sistema epistemológico"? 0 resultado dessa polêmica, hoje apagada pelo tempo, não foi encorajador. G ostaria, porém, de retomar a questão, se eu a compreendi bem, dando-Ihe outra formulação: atual mente, a problemática da cultura encerra algo de qualitativamente diferente em relação às pers pectivas trabalhadas antes? C reio que sim. A tradição das ciências sociais, nos seus diversos ramos disciplinares, confinava a esfera da cultura a certos gêneros específicos: na literatura, a discussão estética; na antropologia, a compreensão das sociedades indígenas, do folclore e da cultura popular; na história, a reflexão sobre as civilizações (hoje revigorada com a emergência da globalização). Tanto na Europa como nos Estados U nidos, a sociologia, quando se ocupava do tema, praticamente o restringia à esfera 
da K ultur. A literatura e a arte desfrutavam assim de um estatuto privilegia do. 0 debate sobre o surgimento da cultura de massa nos Estados $U$ nidos (anos de 1940 e 1950) tomava o universo da arte como referência obrigatória, seja para criticá-la como "elitista" (os autores liberais vinculados à idéia de democracia de massa e ao mercado), seja para valorizá-la, como osfrankfurtianos, como o derradeiro refúgio da liberdade espiritual. Podese ainda dizer que a análise dos fenômenos culturais desfrutavam de um prestígio "menor" no campo intelectual. O utros temas, como partidos políticos, Estado, modernização, industrial ização, urbanização, eram vistos como "mais importantes" do que os estudos referentes à cultura popular, às religiões etc. C erto, a esfera da "alta cultura" permanecia ilesa, pois era considerada al go à parte, o que garantia assim sua aura solitária. M esmo na A mérica Latina, guardadas as devidas proporções, esse movimento se reproduz. C ontrariamente à Europa e aosEstados U nidos, a temática cultural, associada ao dilema da identidade nacional, foi uma preocupação permanente da intelectualidade. $\mathrm{N}$ esse sentido, as análises empreendidas transbordaram os limites estabelecidos pelas ciências sociais européia e norteamericana. A constituição da nação implicava uma reflexão diferenciada. No entanto, na virada dos anos de 1960-1970, com o processo de institucionalização das disciplinas, temas como desenvolvimento, modernização, transição democrática, dependência terão um apelo muito maior entre os cientistas sociais, e um público mais amplo. É possível dizer que a tradição marxista, talvez de forma inconsciente, tenha nisso desempenhado certo papel, poisa"superestrutura", como reflexo ou não da"infraestrutura", designava às manifestações culturais uma posição secundária. D e qualquer maneira, com exceção da antropologia culturalista norte-americana (confinada aos estudos das sociedades indígenas, camponesa, e à aculturação) e a discussão da cultura nacional na A mérica Latina, a esfera da cultura era vista não em sua totalidade, mas recortada segundo temas e disciplinas. 0 s estudos literários pouco tinham a ver com as análises sociológicas, a antropologia dificilmente dialogava com a dimensão "moderna" da chamada "cultura de massa", e assim por diante. A tualmente, em contraposição a essa tendência de compartimentalização do conhecimento, 0 universo da cultura passou a ser percebido como uma encruzilhada de intenções diversas, como se constituísse um espaço de convergência de movimentose ritmos diferenciados: economia, relações sociais, tecnologia etc. $N$ ão creio que venha a existir, como se pensou no passado, uma "Teoria da Cultura" (intenção um tanto ingênua dos antropólogos culturalistas), 
mas estou convencido de que dificilmente esse espaço de convergência pode ser circunscrito às fronteiras canônicas das disciplinas existentes.

0 utro aspecto diz respeito à problemática do poder.Tradicionalmente asciências sociaistenderam a identificá-lo com a política. H á evidentemente exceções que confirmam aregra, por exemplo a sociologia da religião de $M$ axWeber. $N$ ão obstante, o movimento dominante no pensamento sociológico (no sentido amplo do termo) foi considerá-lo algo preferencialmente vinculado ao universo da política. Por isso temas como Estado, governo, partidos, sindicatose movimentos sociais tornaram-se hegemônicos entre os cientistas sociais. A cultura ficava um tanto à margem disso tudo. $\mathrm{N}$ ovamente, diante desse quadro, aA mérica Latina pode ser vista de forma distinta, mas é importante dimensionar as coisas para não cairmos em malentendidos. 0 dilema daidentidade nacional levou a intelectualidade latinoamericana a compreender 0 universo cultural (cultura nacional, cultura popular, imperialismo e colonialismo cultural) como algo intrinsecamente vinculado às questões políticas. Discutir "cultura" de uma certa forma era discutir política. 0 tema da identidade encerrava os dilemase as esperanças relativosà construção nacional. Entretanto, isso posto, éimportante qualificar o contexto no qual o debate era travado e apontar para as mudanças advindas desde então. Primeiro, a emergência de uma indústria cultural, particularmente num país como o Brasil, redefiniu a noção de cultura popular despolitizando a discussão anterior (tratei de maneira exaustiva esse aspecto em meu livro A moderna tradição brasileira [B rasiliense, 1988]). Segundo, o Estado-nação era o pressuposto básico da argumentação desenvolvida.Terceiro, o movimento de institucionalização das ciências sociais, mesmo restringido com a especialização das disciplinas, incentivou a sepa ração entre compreensão da realidade e atuação política.A stransformações recentes deslocam ainda a centralidade do Estado-nação, redefinindo a situação na qual são produzidas as ciências sociais. M uito do que se define por "crise política" associa-se às restrições impostas à sua atuação. Com o processo de globalização ele torna se debilitado, cindindo o elo postulado anteriormente entre identidade nacional e luta política. 0 deslocamento do debate, da identidade nacional para as identidades particulares (étnicas, de gênero, regionais), reflete essa nova tendência. M esmo no quadro dos antigos países "centrais", pode-se dizer que também as instâncias tradicionais da política perdem legitimidade ao se definirem quase que exclusiva mente em termos das fronteiras nacionais (a discussão sobre uma possível "sociedade civil mundial" é um sintoma disso). 0 utra mudança, a meu ver 
profunda, diz respeito a como a esfera da cultura passa a ser percebida. $\mathrm{N}$ a A mérica Latina, como apontei antes, ela era vista como um espaço de ação política, mas não necessariamente, como entendemos hoje, um lugar de poder. 0 u seja, as contradições existentes no seio das manifestações culturais eram imediatamente traduzidas em análises e propostas encampadas pelas instituições tradicional mente consagradas ao "fazer política" : governo, partidos, sindicatos, movimentos sociais. C reio que se torna cada vez mais clara a distinção entre poder e política, pois o poder, como algo imanente às sociedades, às relações sociais, nem sempre se atualiza como política. Entre as manifestaçõesculturais e as instâncias propriamente políticasexistem portanto mediações. Sem elascorre-se o risco de indevidamente "politizar" a compreensão analítica, deixando- se de lado aspectosimportantes, àsvezes definitivos, da constituição de algunsfenômenossociais(estética, religião etc.). D e qualquer maneira, conceber a esfera da cultura como um lugar de poder significa dizer que a produção e a reprodução da sociedade passam necessariamente por sua compreensão (o que é distinto da idéia de "conscientização", muito em voga na América Latina nos anos de 1950 e 1960). D imensão que se acentua no contexto da globalização.

\section{Resumo}

0 texto foi escrito em resposta a um conjunto de perguntas elaboradas por pesquisadores da U niversidade de Stanford. 0 questionário foi enviado a vários pesquisadorese intelectuais latino-americanos, entre os quaiso autor. Procura-se problematizar a existência dos Estudos $\mathrm{C}$ ulturais, tomada como uma realidade inconteste por aqueles que elaboraram o questionário, situando as ciências sociais no contexto da história dos países onde elas se desenvolvem. $N$ esse sentido, os Estudos $C$ ulturais nada têm de "universal", mas são fruto de uma conjuntura específica, sobretudo norte-americana, e dificilmente poderiam reproduzir-se no Brasil e naA mérica Latina da mesma maneira.

Palavras-chave: C ultura; M undialização; C iências sociais, Língua inglesa; M ultidisciplinaridade.

\section{Abstract}

Text written in response to a cluster of questions elaborated by researchers belonging to Stanford U niversity. The questionnaire was sent to several Latin-A merican researchers and intellectuals, including the author himself.T he author tries to argue 
the existence of C ultural Studies, taken for granted from those who made the questionnaire, placing the social sciences in the historical context of the countries in which they have been developing. Cultural Studies are not at all something "universal", being the outcome of very specific circumstances, mainly $\mathrm{N}$ orth A merican, and hardly could be reproduced as such either in Brazil or in Latin America.

Keywords: C ulture; G lobalization; Social sciences; English language; M ultidisciplinarity

$R$ enato 0 rtiz é professor titular do Departamento de Sociologia da U nicamp e autor, entre outros, de C ultura e modernidade (Brasiliense, 1991), M undializ ação e cultura (Brasiliense, 1994), U m outro território: ensaios sobre a mundialização (O lho d’Água, 1996), 0 próximo e o distante: Japão e modernidade-mundo (Brasiliense, 2000) e C iências Sodais e trabaIho intelectual (O Iho d'Água, 2002). 